\title{
Artistic and applied creativity as a factor in the development of constructive relations among pupils of the Kyrgyz orphanage
}

\author{
Gulina Sydykova ${ }^{1, *}$ and Gulzara Baygajanova ${ }^{1}$ \\ ${ }^{1}$ Kyrgyz National University named after Zhusup Balasagyn, 720039, Kyrgyzstan
}

\begin{abstract}
The article examines the problem of the development of constructive relationships among the pupils of the Kyrgyz orphanage through artistic and applied creativity. Children living in an orphanage are characterized by pronounced destructive relationships, impaired social adaptation. Many of the children in the orphanage display destructive patterns of interaction, weakness in conscious regulation of behavior, frequent outbursts of aggression, and a low degree of reflexive activity. These results gave rise to the need to create an author's group methodology. It contains situations and tasks with the use of non-traditional modern materials and stimulating creative games to form constructive interaction between children. As a result of the use of the methodology of group artistic and applied activities among the pupils of the orphanage, there is an increase in the number of positive choices in sociometry. Thus, joint group lessons reduced the level of rejection of each other's pupils, increased cooperation and communication, they became more tolerant of the "outcast" members of their group. In children brought up in an orphanage, in the process of participating in a program of group artistic and applied activities, positive group roles are formed.
\end{abstract}

\section{Introduction}

One of the main conditions for normal integration into society and socialization of children is the presence of a strong family. The emergence of various socially disadvantaged families in society leads to the fact that children find themselves outside the family field, the family resource becomes inaccessible to them. The main intermediary leads children into social cognition of the external world - their parents, but children are deprived of this and, therefore, lose the opportunity for successful social adaptation and socialization. This phenomenon is due to the growth in society of a special category of children who do not have a family field and who have lost the care of their parents, who need special support from other adults and the state.

Children brought up outside the family in an orphanage are characterized by pronounced destructive relationships, impaired social adaptation. Many of the children of the orphanage are characterized by weakness of conscious regulation of behavior, frequent outbursts of aggression, and a low degree of reflexive activity[4]. The presence of maternal and emotional

\footnotetext{
* Corresponding author: gulina-sydykova@mail.ru
} 
deprivation causes high anxiety, fears, and emotional instability. They manifest the "affect of inadequacy", which is expressed in the pupils' misunderstanding that their peers have similar problems and experience the same feelings - they rarely show empathy and sympathy. Orphans are more aggressive, tend to blame others more often, do not know how and do not want to admit their guilt, i.e. in essence, the dominance of protective forms of behavior in conflict situations and the inability to constructively resolve the conflict [4]. In lower grades, pupils do their best to attract attention. Superficial observation suggests a with the need for communication with adults in these children, which leads to certain deviations in behavior $[3]$.

\section{An experimental study}

Our experimental study of the development of favorable relations among children through creativity indicates that this problem has not been studied in Kyrgyzstan. Observations of the pupils of the Center for Social Adaptation of Children (orphanage in Bishkek) showed that the overwhelming majority of them exhibit destructive models of interaction. Children often clashed, did not own the ways of group cooperation, they had a high level of rejection of each other, and demonstrated aggressive, hostile behavior. However, along with this, the pupils experienced a great need for the care, attention and support of an adult mentor. Taking into account these features of the relationship and interaction of children brought up in orphanages in Kyrgyzstan, we have a scientific and practical need to develop ways and methods for the development of constructive relationships among children, therefore, the formation of a positive socio-psychological climate in the orphanage.It was concluded that the features of negative social behavior of children brought up in Kyrgyz orphanages were formed as a result of psychologically unfavorable group experiences that appeared as a result of being in families, in street companies that do not have well-being for the development of children, that is, in the context of certain communication in a group. In this regard, we set the task of reconstructing the peculiarities of the style, the relationship of children from the orphanage through the use of specially designed group creative activities aimed at involving the pupils in artistic and applied art. This type of creativity is a good tool not only for the aesthetic development of Kyrgyz children from an orphanage, but also develops constructive relationships by creating a common creative product. Thus, the main goal of the study was to identify the positive dynamics of the relationship of pupils of the Kyrgyz orphanage as a result of their participation in group art and applied art.

\section{Results}

In order to study the relations of pupils, sociometry with children living in an orphanage was implemented. 


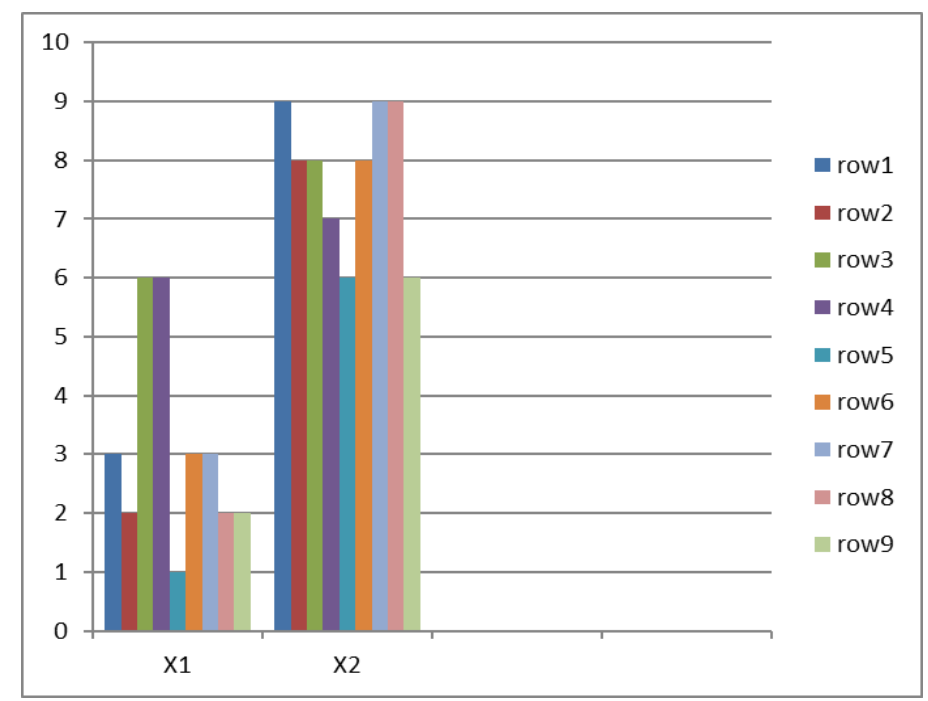

Fig. 1. Rows: 1- Stars; 2- Reference members of the group; 3- Members with two positive choices; 4Members who scored one positive choice; 5- Les Miserables; 6- Non-referential group members; 7-8Members with two negative choices; 9 - Members having one negative choice. Where: x 1 - Positive choices of pupils, $\mathrm{x} 2$ - Negative choices of pupils.

The data obtained indicate that in the groups of pupils there is a high tendency of rejection of each other, unwillingness to live in the same house. These results gave rise to the need to create an author's group methodology. It contains situations and tasks with the use of nontraditional modern materials (dough and mass for modeling, soap, rice) and stimulating creative games to form constructive interaction between children. In creative activities, the main goal was not only the development of creativity, but also the final cooperation of children at the end of the game. Classes in a group with pupils of a Kyrgyz orphanage were held regularly for 5 months. After that, sociometry was reimplemented with children from the orphanage.

Sociometry indicators are reflected in the following diagram (Fig. 2).

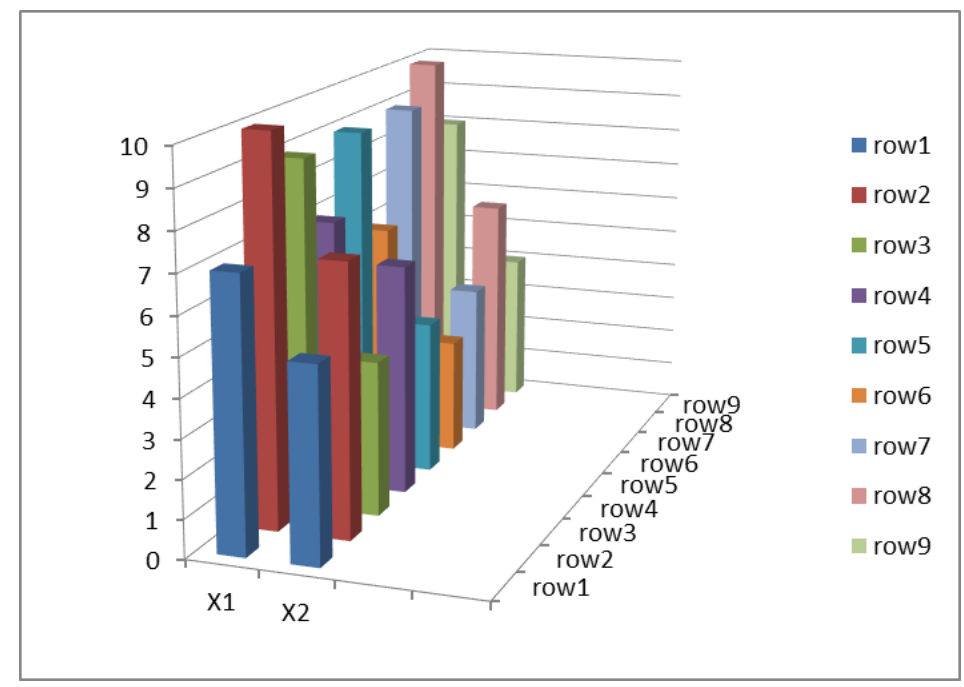

Fig. 2. Data of children's choices after repeated sociometry. Where: $x 1$ - positive choices of pupils, $x 2$ - negative choices of pupils. 
As a result of the use of the methodology of group artistic and applied activities among the pupils of the orphanage, there is an increase in the number of positive choices according to sociometry, and the indicators of the choices of "outcast" children showed positive dynamics. This means that joint group activities have reduced the level of rejection of each other's pupils, increased cooperation and communica-tion, they have become more tolerant of the "outcast" members of their group.

In children, the development of communication was also recorded, an in-crease in interaction in the group, leading to the emergence of cooperation. The activities of children constantly need targeted influence from an adult. Praise, attention and affiliation to each child in the creative process can provide a meaningful and effective level of increasing children's creative motivation and communication. It was also noticed that in a group, children show more initiative, a desire for creativity than with individual performance. The functions of the group creative process are revealed: the creativity of the participants has a positive effect on the relationship with each other; unites their efforts; unites the participants in the process; evokes positive emotions; helps to reduce the level of rejection of the other.

\section{Discussion}

Thus, in the process of group creativity, children began to influence each other, strive for cooperation and social interaction. At the very beginning of classes, children began to better understand the essence of creative games, make suggestions, put forward various options for building joint games. No conflicts were recorded. Creative ideas, transformations of activities, put forward by some of the children, began to positively influence other members of the group. They began to demonstrate their ideas, began to unite in the process of realizing a creative common idea. Bright primary colors began to prevail in children's drawings, flexibility and smoothness in drawings increased (by 25\%). Before this period, the drawings of all the children of the orphanage were notable for their carelessness, lack of fluency. The quality of the drawings of 8-9-year-old children corresponded to the drawings of 6-7-yearolds, in the drawings of 10-year-old children one could find features characteristic of the drawings of 8-year-olds.

Creative activities in a group influenced not only group processes, but also positively influenced mental processes: imagination, thinking, children's attention[2]. Prior to this period, the children of the orphanage were characterized by a low level of cognitive processes[1;5]. Another characteristic of the children in the orphanage is the insufficient development of fine motor skills. Due to this reason, children lag far behind in writing from children from the family. They need constant writing and writing classes, but they quickly lose interest and perform poorly on assignments, begin to avoid, show resistance to implementation. Classes under the program of group artistic and applied activities, including assignments for drawing and modeling, had a good effect on the development of fine motor skills of the hands of children.

\section{Conclusions}

In the process of creative group lessons, children strove for self-expression, strove to discover new sides in themselves. Some pupils who were characterized by unsuccessful studies were unreferential members of the group. With a purposeful, attentive influence, they began to express original ideas, created non-trivial products of creativity. Group discussion and praise influenced children's attitudes. They began to participate in group activities, moved from the position of "non-referential" group members. Other children began to team up with them in group assignments. 
The presence of constructive relationships in children has a beneficial effect on their collective activity, in this study, on artistic and applied. This factor turns such activity for the pupils of the Kyrgyz orphanage into an attractive interaction, because their need for positive interaction and communication is satisfied. A special place in the cooperation of the orphanage pupils is occupied by favorable constructive relations in the children's group, the collective - this is especially important, because they interact every day. Therefore, it is significant to create conditions under which pupils feel comfortable in the children's group, thereby meeting their needs for positive communication, for self-development through the development of creative activity.

\section{References}

1. L.B. Ermolaeva-Tomina, Psychology of artistic creativity (Academic Project, Moscow, 2003)

2. O. Fedotova, V. Latun, Procedia - Social and Behavioral Sciences 191, 1054-1061 (2015)

3. A.M. Prihojan, N.N. Tolstykh, Psychology of Orphanhood. 2 edition (St. Petersburg, 2005)

4. L.M. Shipitsyna, Psychology of orphans. Tutorial (SPbSU, St. Petersburg, 2005)

5. R. Sternberg, General intellectual ability. Human abilities (Cambridge University Press, 2002) 